\title{
EARLY AND LATER LIFE EXPERIENCES OF UNEMPLOYMENT UNDER DIFFERENT WeLfare REgIMES
}

Martina Brandt, Karsten Hank 


\title{
10 Early and Later Life Experiences of Unemployment under Different Welfare Regimes
}

\author{
Martina Brandt and Karsten Hank
}

\subsection{Unemployment in a life course and cross-national perspective}

Involuntary job loss has been shown to be associated with a variety of adverse outcomes, such as lower wages, poorer health, or greater divorce risks (Arulampalam, 2001; Schröder chapter 17 in this volume; Hansen, 2005). It is thus considered as a serious life-disrupting event which may affect - in different ways - labour market entrants as well as older workers (Breen, 2005; Henkens et al., 1996).

A much discussed issue of high policy relevance is the degree to which the experience of unemployment inflicts longer term 'scars', such as an increased likelihood of future unemployment (Gangl, 2004). Due to scarring effects, the total costs of unemployment might be higher than the immediate loss of earnings, thereby increasing lifetime inequality. To address this, one obviously needs to take a life course perspective - which is also important to account for the potential role of childhood conditions (such as parental socio-economic status) in predicting involuntary job loss in adulthood (Caspi et al., 1998).

Moreover, institutional factors - which are often specific to particular welfare state regimes - matter greatly for our understanding of unemployment at various stages of the life course (Blossfeld et al., 2006; Breen, 2005). An issue of particular concern here is the extent to which welfare state interventions, such as active labour market policies, can mitigate longer term scars of previous unemployment experiences (Gangl, 2004; Strandh \& Nordlund, 2008).

Exploiting retrospective information collected in the SHARELIFE project, we track the unemployment experiences of today's elders in 13 Continental European countries from their labour market entry to retirement, addressing the following questions:

How did levels of unemployment in the current SHARELIFE sample vary across different stages of individuals' life course? What does the cross-national pattern of unemployment levels in early-, mid- and later-life look like?

How are childhood conditions associated with unemployment experiences across the adult life course? Are potential associations stronger in the beginning of individuals' employment career, fading-out later on? 
To what extent do we observe scarring effects of unemployment - and variations therein across different welfare regimes - in Continental Europe's contemporaneous older population?

\subsection{Unemployment histories in SHARELIFE - measurement and analysis}

SHARELIFE provides annual work histories of all respondents who reported to have ever done any paid work from the year when they left full-time education till the date of the interview (also see Brugiavini et al. in chapter 11 of this volume). The data allows us to identify periods of unemployment only, if the gap between two jobs (between leaving full-time education and the respondent's first job, respectively) was longer than six months. We restrict our analysis to respondents aged 60 years or older at the time of the SHARELIFE interview. Cases for which the interviewer reported frequent difficulties to understand the questions being asked are excluded from the analysis. This results in a sample of roughly 16,000 observations.

Our main variables of interest are three binary indicators of unemployment periods (any vs. none) during different phases of the individual's career: early (i.e. within the first three years after having left full-time education), prime-age working years (between the end of 'early' and age 49), late (age 50 or over). We use these variables to perform separate analyses of unemployment risks in each career phase. Moreover, information on individuals' previous experience of involuntary job loss enters the models for unemployment during prime-age and later years as an explanatory variable. We interpret significant associations of unemployment in t-1 with the risk of experiencing a period of unemployment in phase t of one's career as indication for scarring effects.

All control variables refer to measures which were determined before the individual first entered the labour market. That is, we exclude potentially relevant factors which themselves might have been affected by earlier experiences of unemployment, such as mid-life health (Schröder, chapter 17 of this volume) or marital status (Hansen, 2005). Next to sex and years of education (derived from SHARE's Wave $1 \& 2$ ) as basic socio-demographic variables, we focus on information regarding respondents' childhood conditions at age ten: self-rated health (ranging from poor [1] to excellent [5]), a composite measure of self-rated maths and language skills (ranging from 'much better' [1] to 'much worse [5] in comparison to other children in the respondent's class), and parents' socio-economic status (operationalised by the number of rooms per person and the number of books available in the household).

Finally, we roughly account for the historical period during which the SHARELIFE respondents graduated (pre-1950, 1950s, 1960 or later) as well as for the respective welfare state context. Starting from Esping-Andersen's (1990) 
initial 'regime' typology we roughly group the countries represented in SHARELIFE into four clusters which we label as social-democratic (DK, NL, $\mathrm{SE}$ ), conservative (AT, BE, CH, DE-W, FR), Mediterranean (ES, GR, IT), and post-communist (CZ, DE-E, PL). Moreover, in a supplementary analysis we take into consideration the labour market situation in each country (except the postcommunist ones) by accounting for the level of unemployment in the year when respondents' left education (Kahn, 2010).

\subsection{Regional and career stage variations in levels of unemployment}

While differences in unemployment levels at various stages of individuals' lifecourse (career, respectively) are rather modest on average (i.e. if the pooled SHARELIFE sample is considered), we observe substantial variations across different welfare state regimes (see Figure 10.1). Consistent with previous research we find the by far highest prevalence of early career unemployment during the post-WWII era in the Mediterranean countries (slightly more than 12\%), which, however, exhibit the lowest unemployment rate - together with the postcommunist countries - among older workers (somewhat less than $3 \%$ ). The reverse is true under the conservative and social-democratic regimes, where unemployment in the first years after leaving education is a relatively minor issue ( $2 \%$ ), but affects more than $8 \%$ of workers aged $50+$ in the conservative and $6 \%$ in the social-democratic countries.

Figure 10.1: Prevalence of unemployment (in \%) at different life-course / career stages across welfare state regimes 


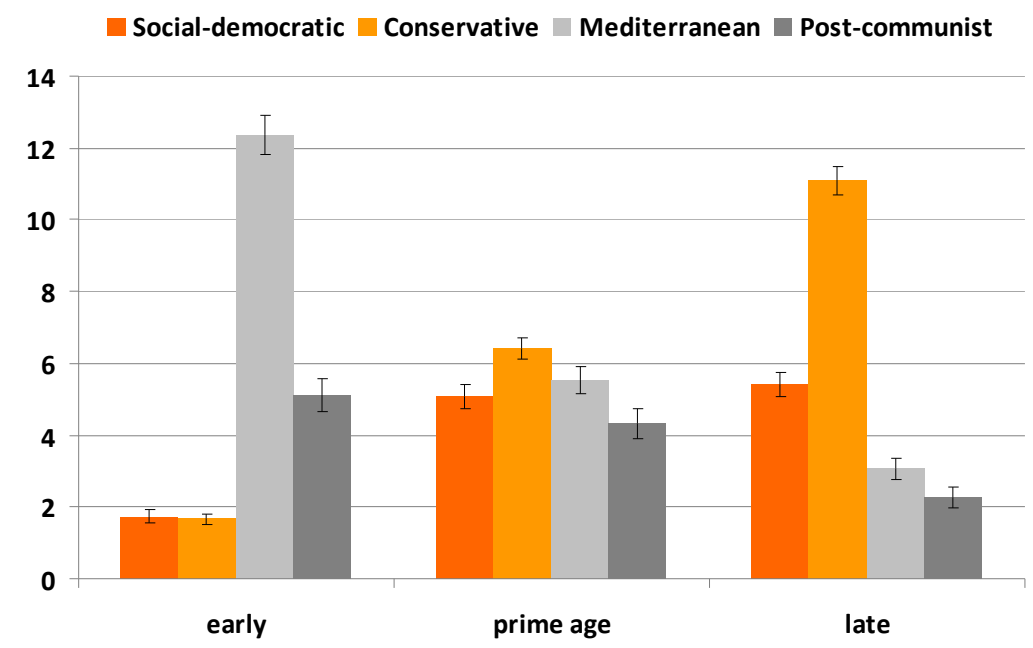

Cross-sectional weights applied; $n=16,231$

\subsection{Correlates of job loss over the life course}

We estimated logistic models for three 'events', namely the experience of at least one unemployment spell during the individual's early, mid-, and late career (see Table 10.1), whose results we discuss jointly.

In the early unemployment model (Model 1), the number of rooms per member of the parental household was the only personal characteristic bearing a statistically significant correlation with the dependent variable. More rooms (supposed to reflect a higher parental SES) were associated with substantially lower odds of being unemployed in the first years after the individual's exit from full time education. This relationship holds for unemployment risks later in life, too. Our composite measure of math and reading skills as well as the number of books in the parental household exhibit the same - but insignificant - outcome in all models. The coefficient of our last measure of childhood conditions, subjective health, was insignificant in the 'early unemployment' model, but suggests that better health at age ten is associated with significantly lower odds of unemployment later in life.

The outcome of other correlates of job loss tends to be quite different before and after age 50, though, both in terms of their sign and statistical significance. Women, for example, are more likely than men to report unemployment before age 50 (probably due to difficulties finding a family friendly job), but they are less likely to be unemployed after age 50 (probably due to an earlier selection of less career oriented women out of the labour force). More years of education significantly reduce the odds of being unemployed before age 50 , but the coefficient is not statistically significant anymore if job losses after age 50 are considered (sug- 
gesting that human capital obtained earlier in life might loose at least some of its 'protective' effect over time).

Turning to our cohort and welfare regime indicators, we - again - observe very similar associations in the models for mid- and late-career unemployment. Those who graduated after 1950, and particularly those who completed their education in the 1960s or later, exhibit significantly higher odds of losing their job than those who left education before 1950. Individuals living under a Mediterranean or postcommunist welfare regime face much smaller unemployment risks in their midand late-career, compared to their counterparts in conservative countries. The same holds for people from social-democratic countries, but note that the respective coefficient in the 'mid-career unemployment' model does not meet the 10\%level of significance. A very different picture, however, emerges when looking at the 'early unemployment' model. There are no cohort differences, individuals from conservative and post-communist regimes do not differ from each other, whereas the odds of job loss are particularly high in the Mediterranean and lowest in the social-democratic countries.

Table 10.1: Odds ratios from logistic regressions for 'early', 'prime-age', and 'late' unemployment

\begin{tabular}{lrcc}
\hline & Model 1: & Model 2: & Model 3: \\
\hline & 'Early' & 'Prime-age' & 'Late' \\
Gender (female) & 0.89 & $1.50^{* *}$ & $0.67^{* *}$ \\
& $(1.38)$ & $(5.40)$ & $(5.56)$ \\
Years of education & 1.01 & $0.95^{* *}$ & 1.00 \\
& $(0.83)$ & $(4.72)$ & $(0.20)$ \\
Childhood conditions & & & \\
Number of rooms per person & $0.59^{* *}$ & $0.74^{*}$ & $0.78^{*}$ \\
& $(3.79)$ & $(2.24)$ & $(2.49)$ \\
Maths \& reading skills & 0.92 & 0.95 & 0.99 \\
& $(1.42)$ & $(0.91)$ & $(0.15)$ \\
Number of books in household & 0.96 & 0.96 & 0.95 \\
& $(0.93)$ & $(0.98)$ & $(1.57)$ \\
Self-rated health & 1.00 & $0.91^{*}$ & $0.92^{*}$ \\
(good or better) & $(0.11)$ & $(2.43)$ & $(2.42)$ \\
Cohort: left education ... & & & \\
... before 1950 & 1.00 & 1.00 & 1.00 \\
... 1950-1959 & 0.91 & $1.70^{* *}$ & $1.70^{* *}$ \\
& $(1.00)$ & $(4.97)$ & $(5.13)$ \\
... 1960 or later & 0.95 & $2.83^{* *}$ & $2.15^{* *}$ \\
& $(0.42)$ & $(9.59)$ & $(7.15)$ \\
\hline
\end{tabular}




\begin{tabular}{lccc}
\hline 'Welfare regime' & & & \\
Social-democratic & $0.66^{* *}$ & 0.87 & $0.68^{* *}$ \\
& $(2.74)$ & $(1.60)$ & $(4.59)$ \\
Conservative & 1.00 & 1.00 & 1.00 \\
Mediterranean & $4.69^{* *}$ & $0.56^{* *}$ & $0.27^{* *}$ \\
& $(14.34)$ & $(5.31)$ & $(10.79)$ \\
Post-communist & 1.14 & $0.40^{* *}$ & $0.21^{* *}$ \\
& $(0.89)$ & $(6.42)$ & $(9.96)$ \\
Previous unemployment & & & \\
'Early' & -- & $2.83^{* *}$ & $1.42^{*}$ \\
& & $(7.57)$ & $(2.06)$ \\
'Prime-age' & -- & -- & $3.00^{* *}$ \\
Pseudo-R2 & & & $(10.15)$ \\
\hline
\end{tabular}

* significant at $5 \%$; ${ }^{* *}$ significant at $1 \%$

z-values in parentheses; robust standard errors

$\mathrm{n}=15,913$

Finally, we find clear indication of scarring effects. There is a large positive total effect of having experienced unemployment in the first three years of one's career on further unemployment risks before and after age 50. Although the odds ratio of our 'early unemployment' indicator in the late-career model (Model 3) is only half the size of the respective odds ratio in the mid-career model (Model 2), the observed correlation even remains highly significant, if unemployment during the prime-age working years (which is also significant) is controlled for in the regression. That is, early- and mid-life experiences of unemployment bear in them independent and strong associations with the risk of losing one's job after the age of 50 .

Additional models employing interactions of 'early' unemployment with gender, cohort, and welfare regimes (details not shown) generally did not provide any additional insights. However, scarring effects among prime-age respondents living in 'social-democratic' and 'post-communist' countries were found to be significantly larger - by a factor of 2 to 3 - than among their counterparts elsewhere.

\subsection{Unemployment as a contextual variable - does it matter?}

One possible explanation for this latter finding has been put forward by Lupi \& Ordine (2002), who argue that in a high youth unemployment environment such as Southern Europe individual unemployment experiences tend to be perceived as 
'normal' and do not necessarily signal poor quality of the worker, as is the case in Northern Europe, where youth unemployment is not an issue of general concern.

To test, whether there is support for this argument in the SHARELIFE sample, we estimated a model in which we controlled for country-level unemployment rates at the time of individuals' exit from education (excluding the formerly communist countries). Since, for the entirety of countries contributing to our sample, this contextual variable is only available from 1960 onwards, we were forced to restrict this part of the analysis to those who left school in that year or later. While we find the expected positive association between individuals' risk of 'early' unemployment and the national unemployment rate in the year when they exited from education, the respective interaction term turned out to bear no statistically significant association with later-life experiences of unemployment (see Table 10.2).

Table 10.2: Odds ratios from logistic regressions for 'early', 'prime-age', and 'late' unemployment in cohorts who left education in 1960 or later

\begin{tabular}{|c|c|c|c|}
\hline & Model 4: & Model 5: & Model 6: \\
\hline & 'Early' & 'Prime-age' & 'Late' \\
\hline \multicolumn{4}{|l|}{ Previous unemployment } \\
\hline \multirow[t]{2}{*}{ 'Early' } & -- & $4.04 * *$ & 0.82 \\
\hline & & $(2.89)$ & $(0.34)$ \\
\hline \multirow[t]{2}{*}{ 'Prime-age' } & -- & -- & $3.4^{* *}$ \\
\hline & & & $(6.83)$ \\
\hline \multicolumn{4}{|l|}{ Context variable } \\
\hline Unemployment rate in year of exit & $1.6^{* *}$ & 0.94 & $0.77^{* *}$ \\
\hline from education (1960+) & $(13.24)$ & $(1.47)$ & $(4.48)$ \\
\hline \multicolumn{4}{|l|}{ Micro-macro interaction } \\
\hline Unemployment rate $X$ & -- & 0.87 & 1.17 \\
\hline early unemployment experience & & $(1.04)$ & $(1.03)$ \\
\hline Pseudo-R2 & 0.12 & 0.04 & 0.05 \\
\hline \multicolumn{4}{|c|}{$\begin{array}{l}\text { Notes: Post-communist countries and respondents who left education before } 1960 \text { are } \\
\text { excluded. All variables displayed in Table 10.1, except welfare regime, are control-led for } \\
\text { in the model. Unemployment rates (in \%), by country and year, retrieved from: }\end{array}$} \\
\hline \multicolumn{4}{|c|}{$\begin{array}{l}\text { http://www.fgn.unisg.ch/eumacro/macrodata/macroeconomic-time-series.html } \\
\text { [05.04.2010] }\end{array}$} \\
\hline \multicolumn{4}{|c|}{$*$ significant at $5 \% ; * *$ significant at $1 \%$} \\
\hline \multicolumn{4}{|c|}{ z-values in parentheses; standard errors clustered by country-year } \\
\hline
\end{tabular}




\subsection{Summary and perspectives for future research}

SHARELIFE allowed us to observe interactions between differences in unemployment across individuals' life-course and across welfare state regimes where, for example, early (late, respectively) unemployment is relatively high (low, respectively) in the Mediterranean countries, whereas the reverse pattern holds under a conservative welfare regime. While the results of our multivariate analysis suggest that welfare state institutions matter at all stages of the individual's employment career, they appear to be particularly relevant in the first three years following the exit from full time education. Different from later career phases, the personal characteristics considered in the 'early unemployment' model barely matter, but we find strong positive (Mediterranean) and negative (socialdemocratic) associations of our welfare regime indicators with younger individuals' unemployment risks. Both labour market institutions as well as elements of a country's educational system, such as employment protection regulations or the vocational specificity of the education system (Breen, 2005), are likely to play an important role here and deserve further attention in future research.

For mid- and late-career workers, the odds of losing one's job bear significant correlations with gender, years of education, and cohort. To some degree, childhood conditions (such as parental SES and the respondent's health) also seem to matter, but the underlying causal mechanisms are not yet well-understood and clearly require further investigation.

Our analysis of SHARELIFE data confirms previous research in that we find clear evidence for scarring effects, even among older workers. We can show that early- and mid-life experiences of unemployment bear in them independent and strong associations with the risk of losing one's job after the age of 50. This observation holds for men as well as for women and is stable across school-leaving cohorts and welfare regimes.

This initial analysis of SHARELIFE is far from being comprehensive and the perspectives for future research are manifold, e.g.:

- How much of the 'total effect' of previous unemployment experiences identified here is mediated through mechanisms related to adverse effects of involuntary job loss on individuals' health (Schröder, chapter 17 in this volume) or marital status (Hansen, 2005), for example?

- What evidence does SHARELIFE provide for scarring effects of unemployment on life-time earnings (Arulampalam, 2001)?

- Further efforts are needed to understand more thoroughly the role of specific welfare state interventions (Gangl, 2004) and the impact of macroeconomic conditions (Lupi \& Ordine, 2002) in the observed variations of unemployment - and its scarring effects - across cohorts and countries. Why, for example, are scarring effects among Scandinavian prime-age workers stronger than in the Mediterranean countries? 


\section{References}

Arulampalam, W. (2001). Is unemployment really scarring? Effects of unemployment experiences on wages. The Economic Journal, 111, F585-F606.

Blossfeld, H.-P., Buchholz, S., \& Hofäcker, D. (eds.) (2006). Globalization, uncertainty and late careers in society. London: Routledge.

Breen, R. (2005). Explaining cross-national variation in youth unemployment. Market and institutional factors. European Sociological Review, Vol. 21, pp. 125-134.

Caspi, A., Entner Wright, B.R., Moffit, T.E., \& Silva, P.A. (1998). Early failure in the labor market: Childhood and adolescent predictors of unemployment in the transition to adulthood. American Sociological Review, Vol. 63, pp. 424-451.

Esping-Andersen, G. (1990). The three worlds of welfare capitalism. Princeton: Princeton University Press.

Gangl, M. (2004). Welfare states and the scar effects of unemployment: A comparative analysis of the United States and West Germany. American Journal of Sociology, Vol. 109, pp. 13191364.

Hansen, H.T. (2005). Unemployment and marital disruption - A panel data study of Norway. European Sociological Review, Vol. 21, pp. 135-148.

Henkens, K., Sprengers, M., \& Tazelaar, F. (1996). Unemployment and the older worker in the Netherlands: Re-entry into the labour force or resignation. Ageing \& Society, Vol. 16, pp. 561-578.

Kahn, L.B. (2010). The long-term labor market consequences of graduating from college in a bad economy. Labour Economics, Vol. 17, pp. 303-316.

Lupi, C. \& Ordine, P. (2002). Unemployment scarring in high unemployment regions. Economics Bulletin, Vol. 10, pp. 1-8.

Strandh, M. \& Nordlund, M. (2008). Active labour market policy and unemployment scarring: A ten-year Swedish panel study. Journal of Social Policy, Vol. 37, pp. 357-382. 